\title{
Retraction Note to: Guadua angustifolia as a Structural Material for Greenhouse Design
}

Eduardo Garzón, Manuel Cano García, Luis Pérez-Villarejo, Sergio Martínez-Martínez and Pedro José Sánchez-Soto

\author{
Retraction Note to: \\ Chapter "Guadua angustifolia as a Structural Material \\ for Greenhouse Design" in: J. L. Ayuso Muñoz et al. (eds.), \\ Project Management and Engineering Research, Lecture \\ Notes in Management and Industrial Engineering, \\ https://doi.org/10.1007/978-3-319-51859-6_14
}

This chapter (Garzón E., Cano García M., Pérez-Villarejo L., Martínez-Martínez S., Sánchez-Soto P. J. (2017) "Guadua angustifolia as a Structural Material for Greenhouse Design”. https://doi.org/10.1007/978-3-319-51859-6_14) has been retracted by the Volume Editors of Ayuso Muñoz J., Yagüe Blanco J., Capuz-Rizo S. (eds) Project Management and Engineering Research. Lecture Notes in Management and Industrial Engineering. Springer, Cham, ISBN 978-3-319-51858-9 because it was previously published in Spanish (Ingenieria Civil, Num 177, Jan-Mar 2015, $\mathrm{p}$ 107). This was not made clear in the Springer publication. All authors agree to this retraction.

The retracted chapter and book have been updated with the changes.

The retracted version of this chapter can be found at

https://doi.org/10.1007/978-3-319-51859-6_14 